\title{
Forebay use and entrainment rates of resident adult fish in a large hydropower reservoir
}

\author{
Eduardo G. Martins ${ }^{1, *}$, Lee F. G. Gutowsky ${ }^{1}$, Philip M. Harrison ${ }^{2}$, \\ David A. Patterson ${ }^{3}$, Michael Power ${ }^{2}$, David Z. Zhu ${ }^{4}$, Alf Leake ${ }^{5}$, Steven J. Cooke ${ }^{1}$ \\ ${ }^{1}$ Fish Ecology and Conservation Physiology Laboratory, Ottawa-Carleton Institute for Biology, Carleton University, \\ 1125 Colonel By Dr., Ottawa, Ontario K1S 5B6, Canada \\ ${ }^{2}$ Department of Biology, University of Waterloo, 200 University Ave., Waterloo, Ontario N2L 3G1, Canada \\ ${ }^{3}$ Fisheries and Oceans Canada, Cooperative Resource Management Institute, \\ School of Resource and Environmental Management, Simon Fraser University, Burnaby, British Columbia V5A 1S6, Canada \\ ${ }^{4}$ Department of Civil and Environmental Engineering, University of Alberta, Edmonton, Alberta T6G 2W2, Canada \\ ${ }^{5}$ Environmental and Social Issues, BC Hydro, 6911 Southpoint Drive, Burnaby, British Columbia V3N 4X8, Canada
}

\begin{abstract}
Fish entrainment occurs when individuals are displaced from reservoirs to downstream waters by way of water diversion through turbines or other water release structures. While much effort has been put into quantifying and reducing entrainment of downstream migrating salmonids, considerably less research has focused on fish that are residents in reservoirs and in many cases are the top piscivores in these systems. We used $2 \mathrm{yr}$ of acoustic telemetry data on adult bull trout Salvelinus confluentus and burbot Lota lota tagged in Kinbasket Reservoir (British Columbia, Canada) to investigate entrainment vulnerability by measuring forebay use and entrainment rates. Our results revealed that (1) adult bull trout and burbot made little use of the forebay; (2) bull trout used the forebay more and had higher rates of entrainment than burbot; and (3) both forebay use and entrainment varied among seasons. Bull trout used the forebay more intensively and were mostly entrained in the fall and winter. Limited forebay use and entrainment data for burbot suggest that they are more vulnerable to entrainment in the fall. These findings should be generally applicable for adult bull trout and burbot in reservoirs that maximize operations in the fall and winter, and could help managers and industry to make informed decisions on how to mitigate and compensate for entrainment.
\end{abstract}

KEY WORDS: Entrainment $\cdot$ Hydropower $\cdot$ Bull trout $\cdot$ Burbot $\cdot$ Forebay $\cdot$ Turbines $\cdot$ Acoustic telemetry $\cdot$ Detection efficiency

\section{INTRODUCTION}

Fish entrainment - the displacement of individuals from reservoirs to downstream waters by way of water diversion through turbines or other water release structures (Johnson et al. 2004) — can directly result in injury or death of individuals, as well as reduce the abundance of upstream populations and increase the abundance of downstream populations (reviewed in Coutant \& Whitney 2000). To date, most of the efforts to quantify and reduce entrainment from reservoir operations have focused on downstream-migrating salmonids (e.g. Thorne \& Johnson 1993, Mathur et al. 2000, Scruton et al. 2002, 2008). In those instances, a variety of bypass structures attempt to direct smolts or downstream migrating adults (for iteroparous species) safely past turbines (Coutant \& Whitney 2000, Schilt 2007). However, resident species (i.e. those that do not emigrate from reservoirs) are also vulnerable to entrainment when they use habitats near water intake structures, with vulnerability to entrainment varying with factors such as species, life stage, time of day, 
season and operations (Coutant \& Whitney 2000, Grimaldo et al. 2009, Spinelli 2010).

Detailed studies of entrainment of adult resident fish in western North America have focused on small pelagic planktivores such as kokanee Oncorhynchus nerka and have noted strong and predictable diel and seasonal patterns of entrainment through hydropower turbines (e.g. Maiolie \& Elam 1996, Skaar et al. 1996). Considerably less research has focused on the adults of other resident populations of fish that in many cases are the top piscivores in reservoirs and are represented by relatively long-lived, slow-growing species (e.g. rainbow trout Oncorhynchus mykiss, walleye Sander vitreus, bull trout Salvelinus confluentus, burbot Lota lota) (see review in CH2M HILL 2007). Given that even low levels of adult mortality have the potential to greatly impact the demography of such species, understanding the factors associated with the entrainment of resident adult fish is important for the development of models to predict population-level consequences of entrainment and explore management measures to reduce its impacts. For example, assessing the population-level consequences of entrainment can help managers make informed decisions on the implementation of compensation plans (e.g. habitat improvement), whereas identifying the seasons and times of day when entrainment is more likely to occur could provide information to help optimize the timing of operation of deterrent devices (e.g. strobe lights).

In this paper, we investigated entrainment vulnerability of resident adult bull trout and burbot in a large hydropower reservoir (Kinbasket Reservoir, Mica Dam) in British Columbia, Canada. Recent risk-screening exercises, based on expert opinion and literature reviews of species-specific life history characteristics and habitat use, concluded that adult bull trout and burbot were at moderate risk of entrainment at the Mica Dam (BC Hydro 2006, 2009). However, these analyses also identified uncertainties with regard to bull trout and burbot entrainment, particularly in speciesspecific differences in entrainment vulnerability (i.e. intensity of forebay use) and seasonal rates of entrainment. Given that adult bull trout are more mobile than adult burbot (Harrison et al. 2013), we hypothesized that bull trout are more likely to encounter and use the forebay and hence become vulnerable to entrainment. We also hypothesized that bull trout would have a stronger seasonal pattern of entrainment vulnerability than burbot because adult bull trout are known to undergo seasonal spawning migrations into streams (Dunham et al. 2008). Finally, given that habitat use in fishes can vary between day and night (Helfman 1993), between males and females (Hanson et al. 2008), and ontogenetically (Ross 1986), we also evaluated if forebay use is associated with diel period, sex and size.

\section{MATERIALS AND METHODS}

\section{Study site}

Kinbasket Reservoir $\left(52^{\circ} 8^{\prime} \mathrm{N}, 118^{\circ} 28^{\prime} \mathrm{W}\right)$ is a large glacial- and snowmelt-fed reservoir located about $150 \mathrm{~km}$ north of Revelstoke in the north Kootenay Mountain region of British Columbia, Canada (Fig. 1a,b). The reservoir covers an area of 43200 ha

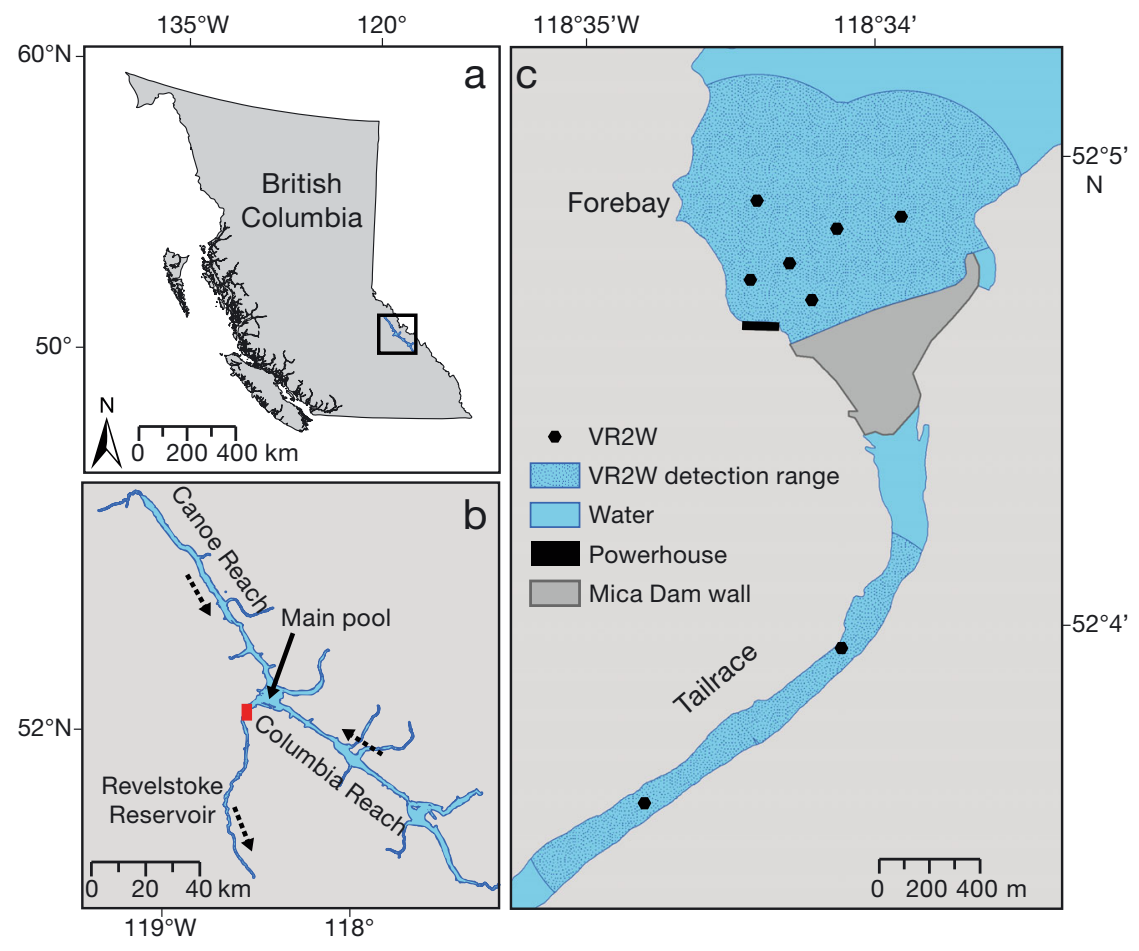

Fig. 1. (a) British Columbia showing the location of Kinbasket Reservoir (open square); (b) Kinbasket Reservoir showing the location of the forebay and tailrace (red square); and (c) Mica Dam forebay and tailrace showing the locations of VR2Ws and their combined expected detection range based on a radius of $500 \mathrm{~m}$ around each receiver. The main pool indicated by a solid arrow in (b) is the confluence of the Canoe and Columbia reaches. Dashed arrows in (b) indicate the direction of water flow 
and was formed by the impoundment of the Canoe and Columbia Rivers with the construction of the Mica Dam in 1973. The reservoir is oligotrophic and characterized by steep rocky shorelines, sand, rock and mud substrates, and little vegetation. At its highest elevation (high pool), the reservoir has a mean depth of $57 \mathrm{~m}$ and maximum depth of about $190 \mathrm{~m}$ that is located in the forebay (Sebastian et al. 1995). Surface water temperatures in the reservoir range from 2 to $15^{\circ} \mathrm{C}$ in early spring, with summer surface temperatures typically between 12 and $18^{\circ} \mathrm{C}$ (Bray 2012). From mid-summer to early fall, a gradual thermal gradient is usually formed in the reservoir, with temperatures decreasing to $4^{\circ} \mathrm{C}$ at $60 \mathrm{~m}$ (Bray 2012).

The powerhouse at Mica Dam currently consists of 4 Francis-type turbines that each have a rated maximum flow of $283 \mathrm{~m}^{3} \mathrm{~s}^{-1}$ and a capacity of $465 \mathrm{MW}$ (BC Hydro 2006). The top of the intakes is located at a depth of about $55 \mathrm{~m}$ during high pool and the turbines are used approximately $95 \%$ of the time, with generation being maximized during the day (BC Hydro 2006). However, operation at the Mica Dam powerhouse is markedly seasonal, with drawdown starting in mid-summer and lasting until mid-April in preparation for the spring freshet (BC Hydro 2006). During the 2 monitoring years of this study, the mean total daily operational discharge at the Mica Dam powerhouse varied substantially on a daily basis (6.3 to $1177.0 \mathrm{~m}^{3} \mathrm{~s}^{-1}$ ), being greater during the fall and winter (Fig. S2 in the Supplement at www.int-res. com/articles/suppl/b019p253_supp.pdf).

The mean water surface elevation of the reservoir (hereafter reservoir elevation) varies seasonally as a result of the spring freshet and drawdown and can change by as much as $47 \mathrm{~m}$ under normal operating elevation ranges (i.e. between 707.0 and $754.4 \mathrm{~m}$ ). The reservoir reaches its lowest elevation (low pool) in the early to mid-spring and its highest elevation (high pool) by late summer or early fall (BC Hydro 2006). Mean daily reservoir elevation during the 2 monitoring years of this study ranged from 723.7 to $754.2 \mathrm{~m}$, resulting in a maximum change in elevation of $30.5 \mathrm{~m}$.

\section{Fish capture and tagging}

Adult bull trout (>300 mm; Scott \& Crossman 1998) were captured throughout the Kinbasket Reservoir main pool (Fig. 1b) by trolling in the early spring of 2010. Bull trout were also captured by angling near the mouths of spawning tributaries at the upper Canoe and Columbia reaches (Fig. 1b) in the late summer of 2010. Capture yielded minimal injury or evidence of short-term mortality (Gutowsky et al. 2011). In total, 187 (109 males, 72 females, 6 uncertain sex) captured bull trout were tagged with an acoustic transmitter (see tagging details below). The average total length of the tagged bull trout was $591 \mathrm{~mm}( \pm 95 \mathrm{~mm} \mathrm{SD}$, min to max: 355 to $881 \mathrm{~mm})$ and their median mass was $1784 \mathrm{~g}$ (inter-quartile range [IQR]: $1426 \mathrm{~g}$, $\min$ to $\max : 310$ to $5857 \mathrm{~g}$ ).

Adult burbot (>300 mm; Scott \& Crossman 1998) were captured using baited cod traps set at several locations throughout the reservoir main pool in the early spring of 2010 and 2011. Since traps were set in deep water (up to $27 \mathrm{~m}$ ), decompression procedures were carried out before landing burbot to reduce the risks of barotrauma. Decompression consisted of holding fish in traps for $24 \mathrm{~h}$ at a depth that was approximately half of the initial capture depth (Neufeld \& Spence 2004). When fish were caught at a depth greater than $15 \mathrm{~m}$, a second $24 \mathrm{~h}$ decompression period was implemented at a quarter of the initial capture depth. In total, 75 (4 males, 24 females, 47 uncertain sex) captured burbot were tagged with acoustic transmitters. The median total length and mass of the tagged burbot was $561 \mathrm{~mm}$ (IQR: $121 \mathrm{~mm}$, min to max: 425 to $975 \mathrm{~mm}$ ) and $794 \mathrm{~g}$ (IQR: $397 \mathrm{~g}$, min to max: 465 to $4801 \mathrm{~g}$ ), respectively.

Landed fish were anaesthetized using clove oil (40 and $90 \mathrm{mg} \mathrm{l}^{-1}$ of clove oil emulsified in $95 \%$ ethanol at a 1:9 ratio for bull trout and burbot, respectively). Following loss of equilibrium, total length $(\mathrm{mm})$ and mass (g) were measured. Fish were surgically tagged with temperature- and pressure-sensing acoustic transmitters (model VEMCO V13TP-1L, dimensions: $45 \times 13 \mathrm{~mm}$, weight in water: $6 \mathrm{~g}$, weight in air: $12 \mathrm{~g}$, signal transmission rate: random between 60 and $180 \mathrm{~s}$ [mean $120 \mathrm{~s}$ ], expected battery life: $1028 \mathrm{~d}$, VEMCO Division, AMIRIX Systems). Briefly, fish were placed on a V-shaped trough where the gills were continuously irrigated with ambient reservoir water. A small incision (20 to $30 \mathrm{~mm}$ ) was made to one side of the ventral midline, 30 to $50 \mathrm{~mm}$ posterior to the pectoral fins, and the fish was sexed visually by examining the gonads. The acoustic tag (cleaned with betadine) was inserted into the coelomic cavity and the incision was closed with 3 to 4 simple interrupted sutures (Ethicon 3-0 PDS II monofilament absorbable suture material, Johnson \& Johnson) (Wagner et al. 2011). Fish were then placed in a recovery box filled with ambient reservoir water and released at the capture site once they regained equilibrium. Burbot were recompressed at depth if showing significant signs of barotrauma (Neufeld \& Spence 
2004). Briefly, this involved placing burbot back in the trap and sinking it down to about $10 \mathrm{~m}$ for $24 \mathrm{~h}$. The shallow recompression depth and short handling time ( $<1 \mathrm{~min}$ ) enabled us to safely pull the net back to the surface and quickly release recovered burbot, without risking further barotraumas. Only fish that met the maximum $2 \%$ tag burden computed as tagweight-in-water divided by fish-weight were tagged (Cooke et al. 2013). The maximum tag burden was $1.9 \%$ and $1.3 \%$ for bull trout and burbot, respectively. Tagging and recovery typically took between 10 and $15 \mathrm{~min}$ for bull trout and 15 and $20 \mathrm{~min}$ for burbot.

Permits to capture fish were issued by the British Columbia Ministry of Environment (Permit No. CBPG10-61414). Tagging protocols were approved by the Carleton University Animal Care Committee.

\section{Telemetry array}

A total of 42 omni-directional hydrophone acoustic telemetry receivers (VR2W, VEMCO Division, AMIRIX Systems) were deployed throughout Kinbasket Reservoir in the spring of 2010. For the purposes of this paper, we used detection data collected by only 6 VR2Ws that were deployed in the dam forebay (Fig. 1c). Additionally, 2 VR2Ws were deployed downstream of the Mica Dam tailrace to provide postentrainment detection of tagged fish (Fig. 1c). One VR2W was deployed in the spring of 2010 and another in the spring of 2011. However, one of the VR2Ws was lost before we returned to download the data in the spring of 2012. Therefore, detection data in the tailrace is available for only 1 VR2W in each monitoring year. Beacon tags were deployed along with each one of the VR2Ws in the forebay to assess detection efficiency (see the Supplement). All data presented here were collected by the forebay and tailrace VR2Ws between May 2010 and April 2012.

\section{Data processing}

The detection data were incorporated into a Microsoft Access ${ }^{\circledR}$ database and processed to include only valid detections (see Beeman \& Perry 2012). Due to the low and variable detection efficiency of the forebay VR2Ws (Fig. S4 in the Supplement), it was not feasible to detect false positives based on the number of detections within a given time period (Beeman \& Perry 2012). Alternatively, we regarded false positives as those detections for which no temperature or depth sensor data were recorded. To avoid any potential short-term effects of tagging on fish behaviour, detections were excluded if they occurred within $7 \mathrm{~d}$ of tagging a fish. To identify individuals that had died or shed a tag near a VR2W, depth sensor data from the tags were plotted by time for each fish. Those presumably deceased individuals $(\mathrm{n}=11)$ showed a long depth record that, after accounting for changes in reservoir elevation, translated to a nearly constant elevation for the fish.

Each detection was classified according to the diel period, season and year when it occurred. Diel period was determined by comparing the detection time to the times of sunrise and sunset at Kinbasket Reservoir (data freely available at www.nrc-cnrc.gc.ca/ eng/services/sunrise/index.html). Seasons were defined as spring (April to June), summer (July to September), fall (October to December) and winter (January to March). The year variable was defined based on monitoring year (i.e. first monitoring year: May 2010 to March 2011; second monitoring year: April 2011 to March 2012). This classification was used so that each year contained all 4 seasons to facilitate analyses involving interactions.

\section{Data analyses}

To evaluate forebay use by bull trout and burbot, we computed the proportion of detections recorded in the forebay ( $\mathrm{pDF}$ ) by diel period, season and monitoring year for each fish. This proportion was computed by dividing the number of detections of a tagged fish at the forebay VR2Ws by the expected number of detections for a hypothetical fish residing exclusively in the forebay area covered by the VR2Ws expected maximum detection range (Fig. 1c). Due to the large seasonal variation in the forebay VR2Ws detection efficiency, presumably due to the seasonality in operational discharge and weather, the expected number of detections was computed through simulations. Briefly, we first modelled detection efficiency by diel period, season, monitoring year and distance between beacon tag and VR2W. Then we used the model to simulate the expected number of detections for a hypothetical tagged fish performing a correlated random walk (Kareiva \& Shigesada 1983) inside the expected maximum detection range of the forebay VR2Ws (see details in the Supplement). For each tagged fish, the simulations generated up to 16 nonindependent replicates of pDF values (1 for each diel period, season and monitoring year combination that a fish was known to be in the reservoir). 
Due to the excessively large number of zero pDF data (85\% for bull trout and $97.7 \%$ for burbot), it was not possible to adequately use and validate models fit to the full data set of each species. Therefore, the data and analyses presented in this paper refer only to cases where fish were detected in the forebay. The pDF values presented in the 'Results' (as \%DF, see below) can then be interpreted only as a measure of how much a tagged fish encountering the forebay used this area compared to a hypothetical fish that would make full time use of the forebay. Burbot pDF data were too sparse for statistical modelling, even after the removal of zero proportions, and are only described in the 'Results'.

Before analysing bull trout pDF data, data exploration was conducted in an attempt to identify the presence of outliers and evaluate the relationship between variables (Zuur et al. 2010). Only interactions clearly indicated by exploratory interaction plots were included in the analysis. We analysed logit-transformed pDF data (Warton \& Hui 2011) as a function of total length and all possible 2-way interactions between diel period, season and monitoring year using linear mixed-effects models (Pinheiro \& Bates 2000), where the intercept was allowed to vary by fish. The analysis followed the general protocols described by Pinheiro \& Bates (2000) and Zuur et al. (2009). Briefly, a continuous auto-regressive function of order 1 (CAR-1) and variance structure were incorporated in the full model to account for residual autocorrelation and heterocedasticity, respectively. Subsequently, a backward model selection procedure was carried out based on marginal F-tests. The reduced model containing only significant predictors was then re-fitted to a subset of the data for which sex information was available to evaluate any possible differences in pDF between females and males. All model assumptions were checked graphically (Zuur et al. 2009).

Entrainment rates were computed from the first detection of each entrained fish at the tailrace VR2Ws using time-to-event analysis (Kaplan-Meier estimator), where season was used as the time unit. The time-to-event analysis enabled us to account for changes in the total number of fish available to be entrained in any season by censoring individuals from the data set when they were lost to monitoring, thus avoiding biases in entrainment rate estimates (Harrell 2001). In our study, those individuals lost to monitoring were represented by tagged fish captured and reported by anglers, or re-captured by our team, or not detected anywhere in the reservoir for more than 1 season (e.g. possible non-reported angler removals, tag loss/failure or natural mortality). Although we did not deploy beacon tags to assess detection efficiency of the tailrace VR2Ws, the time interval between sequential detections of entrained fish was generally within the minimum (60 s) and maximum (180 s) limits of the tags transmission interval (median: $120 \mathrm{~s}$, IQR: $60 \mathrm{~s}$ ). This indicates that detection efficiency in the tailrace VR2Ws was nearly $100 \%$ and, therefore, entrainment rates estimated using time-to-event analysis were not biased by low detection efficiency.

All continuous variables were centred before analysis (i.e. the mean of each variable was subtracted from all of its values). Any post-hoc multiple comparison testing presented was based on Tukey's test (Quinn \& Keough 2002). Central tendency values are presented either as means \pm 1 SD (for normally distributed data) or medians and IQR (for non-normally distributed data). For presentation, all observed and estimated pDF values were multiplied by 100 and are presented as \%DF. The critical value used in interpreting statistical significance was $\alpha=0.05$. The analyses were conducted using the packages 'nlme' (Pinheiro et al. 2012), 'survival' (Therneau 2012) and 'multcomp' (Hothorn et al. 2008) in R version 2.15.1 (R Development Core Team 2012).

\section{RESULTS}

\section{Bull trout}

In total, 66282 valid detections, corresponding to 97 bull trout $(51.9 \%$ of the total tagged), were recorded on the forebay VR2Ws. The median \%DF was only $0.34 \%(1.70 \%$ IQR) and varied little by diel period and monitoring year, but varied substantially among seasons (Fig. 2). The highest \%DF values ( $>10 \%$ for $18 \mathrm{fish} ;>50 \%$ for 4 fish) were observed in the winter (Fig. 2). Backward model selection supported the seasonality observed in \%DF, with the reduced model including an interaction between season and monitoring year (Table 1). Total length and diel period were not retained in the final model (Table 1). Furthermore, the analysis of a subset of the data for which sex information was available did not reveal any significant differences in \%DF between females $(0.37 \%$ with $1.81 \%$ IQR) and males $(0.29 \%$ with $1.49 \%$ IQR) $\left(F_{1,93}=0.07, \mathrm{p}=0.80\right)$.

Post-hoc comparisons among seasons within the first monitoring year revealed that \% DF was 9.7, 35.5 and 5.2 times higher in the winter compared with the spring, summer and fall, respectively (all $-8.5<z<$ 


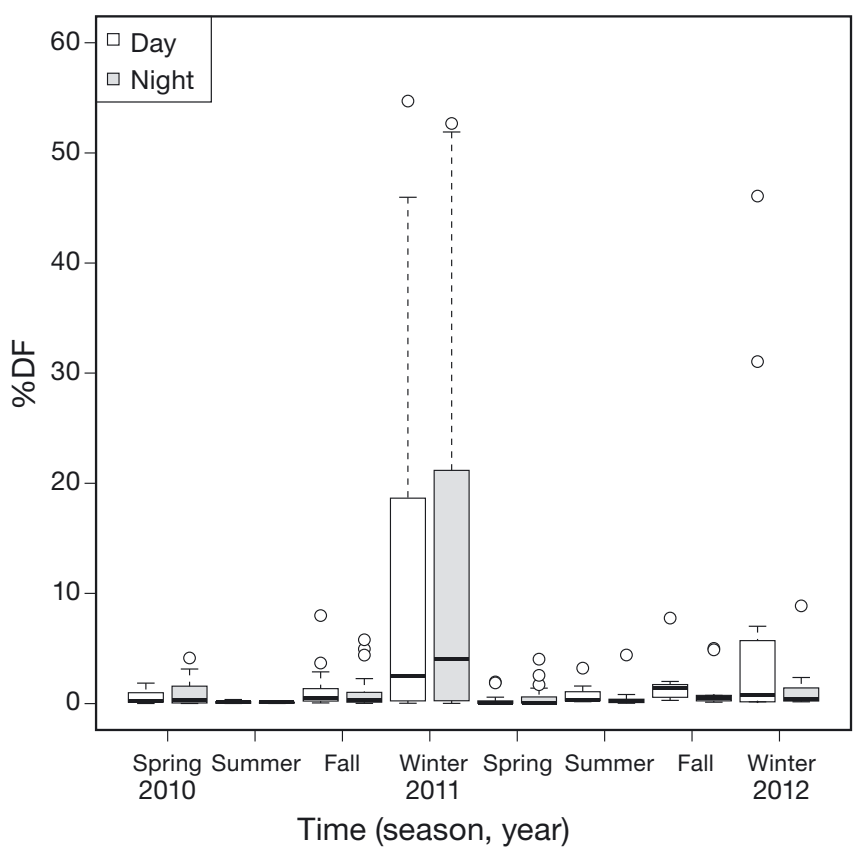

Fig. 2. Salvelinus confluentus. \%DF (i.e. percentage of detections recorded in the forebay) by diel period, season and year for bull trout in Kinbasket Reservoir. Box plot shows the median values (line), 25 and $75 \%$ quantiles (box), values $<1.5$ times the interquartile range (whiskers), and outliers (circles)

$-5.0, \mathrm{p}<0.001)$. Percent detection in the forebay in the fall of the first monitoring year was also significantly higher than in the summer (6.8-fold; $z=-4.9$, $\mathrm{p}<0.001$ ), but not significantly different from that of the spring $(z=-1.5, p=0.73)$. In the second monitoring year, there was no significant difference in \%DF among summer, fall and winter (all $-1.5<z<-0.3$, $\mathrm{p}>0.84)$. However, $\% \mathrm{DF}$ in these seasons were, respectively, 3.8, 6.5 and 6.5 times higher compared with the spring (all $-5.0<z<-3.5, \mathrm{p}<0.001$ ).
Eight bull trout $(4.3 \%$ of the total tagged) were detected on the VR2Ws deployed in the tailrace, resulting in a cumulative entrainment of $6.7 \%$ (i.e. accounting for censoring of fish caught and reported by anglers [ $\mathrm{n}=5]$, recaptured by our team $[\mathrm{n}=1]$ and non-reported angler captures, suspected mortalities and/or tag loss/failure over the 2 monitoring years [ $\mathrm{n}=90]$ ). All but 1 entrained fish were first detected on the tailrace VR2Ws in the fall or winter of both monitoring years (Fig. 3). The exception is an individual that was first detected in the tailrace in the spring of 2012, though it was last detected in the reservoir during mid-winter. The elapsed time between the last detection in the reservoir and the first detection in the tailrace ranged from 0 to $34 \mathrm{~d}$ for fish $(\mathrm{n}=4)$ that were last detected in the forebay, and from 5 to $38 \mathrm{~d}$ for fish $(\mathrm{n}=4)$ that were last detected in the main pool (i.e. that were missed by the forebay VR2Ws). For those individuals that were last detected in the forebay prior to entrainment, \% $\mathrm{DF}$ in the season that they were entrained ranged from 0.03 to $21.0 \%$. Both males $(n=5)$ and females $(n=3)$ were entrained and the total length of entrained fish (440 to $701 \mathrm{~mm}$ ) comprised most of the range of total length of the tagged fish (355 to $881 \mathrm{~mm}$ ).

\section{Burbot}

In total, 349 valid detections, corresponding to 6 burbot ( $8 \%$ of the total tagged), were recorded at the forebay VR2Ws. Only 9 of these 349 detections occurred in the second monitoring year (all during the fall). Overall, burbot using the forebay were infrequently detected in relation to the expected number of detections (Fig. 4). Indeed, the median

Table 1. Estimates of the reduced model describing logit-transformed pDF (i.e. proportion of detections recorded in the forebay) data for bull trout. The table shows the model coefficient estimates, standard error (SE), degrees of freedom (df), $t$-test statistic $(t)$ and $\mathrm{p}$-value (p). Also shown are the standard deviation (SD) for the random intercept and residuals, and the residual correlation $(\phi)$ between sequential observations of any given fish estimated with a continuous auto-regressive correlation structure of order 1 (CAR-1)

\begin{tabular}{|c|c|c|c|c|c|c|c|}
\hline Model coefficient & Estimate & $\mathrm{SE}$ & df & $t$ & $\mathrm{p}$ & Other & Value \\
\hline Intercept & -5.50 & 0.19 & 220 & -28.31 & $<0.001$ & Random intercept SD & 0.49 \\
\hline Season & & & & & & Residual SD & 1.74 \\
\hline Spring & -0.58 & 0.39 & 220 & -1.50 & 0.14 & CAR-1 $\phi$ & 0.13 \\
\hline Summer & -1.88 & 0.39 & 220 & -4.85 & $<0.001$ & Number of observations & 342 \\
\hline Winter & 1.67 & 0.33 & 220 & 5.00 & $<0.001$ & Number of groups (i.e. fish) & 97 \\
\hline Monitoring year (Second) & 0.51 & 0.43 & 220 & 1.20 & 0.23 & & \\
\hline \multicolumn{8}{|l|}{ Season $\times$ Monitoring year } \\
\hline Spring $\times$ Second & -1.63 & 0.60 & 220 & -2.70 & 0.01 & & \\
\hline Summer $\times$ Second & 1.28 & 0.65 & 220 & 1.96 & 0.05 & & \\
\hline Winter $\times$ Second & -1.52 & 0.68 & 220 & -2.23 & 0.03 & & \\
\hline
\end{tabular}




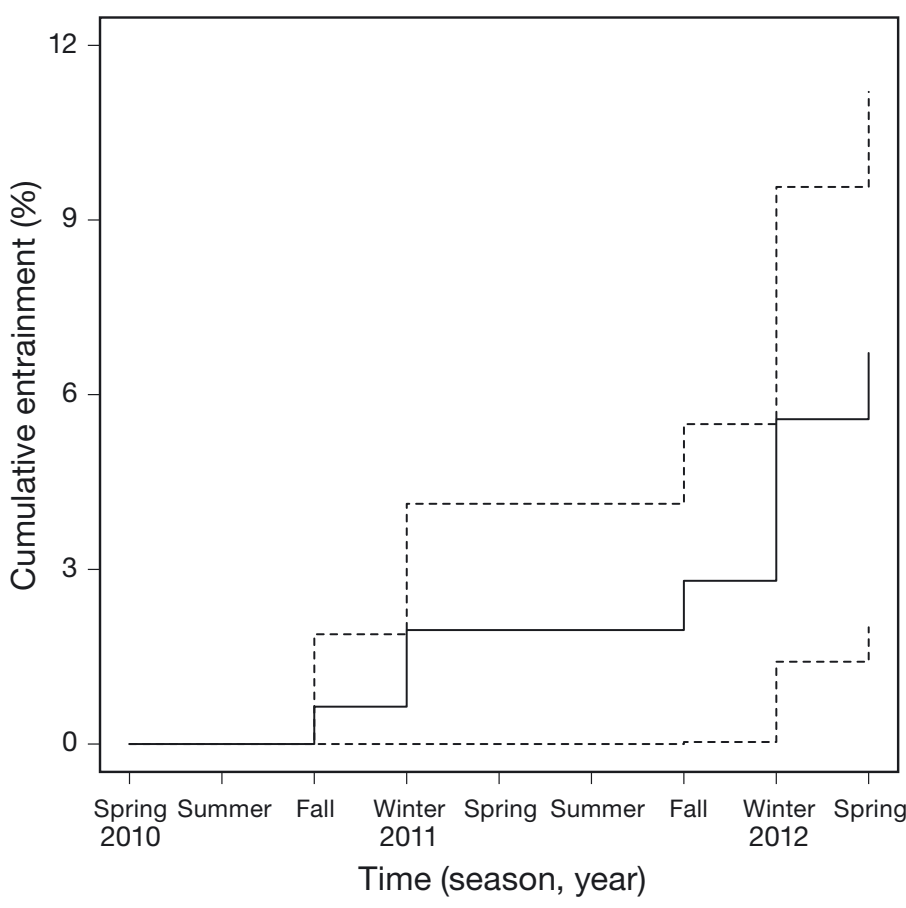

Fig. 3. Salvelinus confluentus. Kaplan-Meier estimates of cumulative entrainment of bull trout through the Mica Dam by season and year. Dashed lines denote $95 \%$ confidence intervals

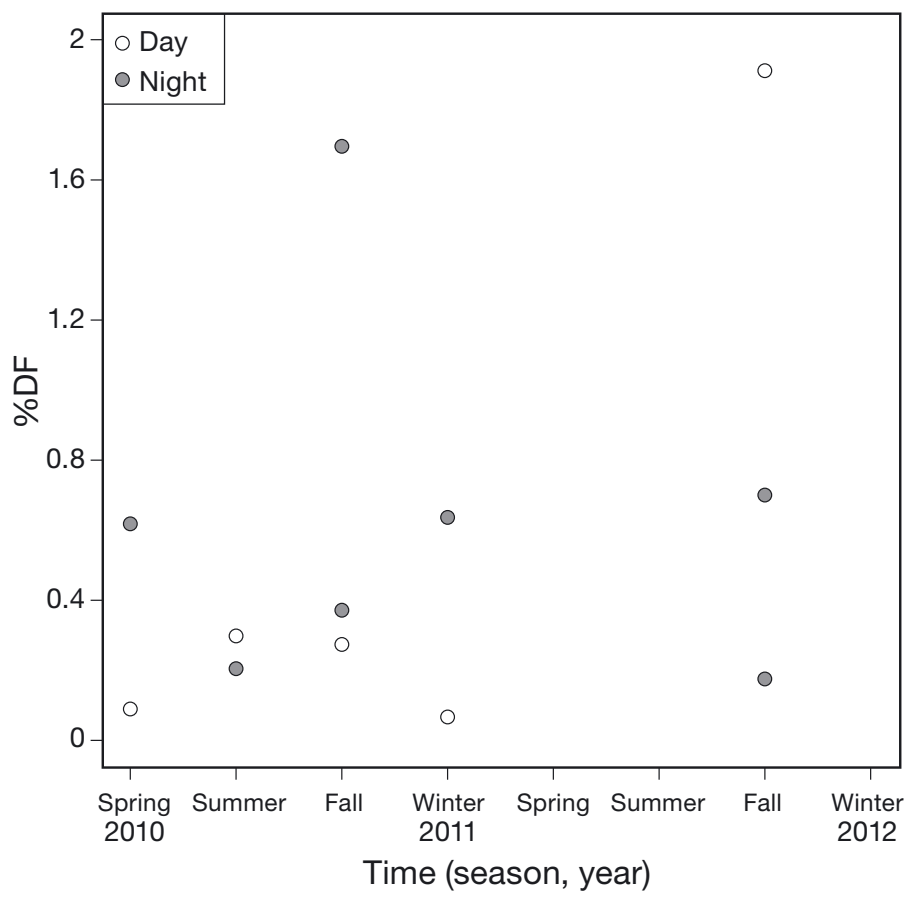

Fig. 4. Lota lota. \%DF (i.e. percentage of detections recorded in the forebay) by diel period, season and monitoring year for burbot in Kinbasket Reservoir. Each data point corresponds to a $\% \mathrm{DF}$ value for an individual burbot
$\%$ DF was only $0.33 \%(0.46 \%$ IQR). The highest \%DF values $(\sim 2 \%)$ for burbot were observed in the fall of both monitoring years (Fig. 4).

Only 1 burbot (1.3\% of the total tagged) was detected on a tailrace VR2W over the 2 monitoring years, resulting in a total entrainment of $1.9 \%$ (i.e. accounting for censoring of possible non-reported fisheries capture, suspected mortalities and/or tag loss/failure until the time of entrainment [ $\mathrm{n}=15]$ ). The total length of this individual was $442 \mathrm{~mm}$ and its sex was unknown. Its last detection in the reservoir (at a VR2W in the main pool) and first detection in the tailrace occurred in the fall of 2010 (23 d apart).

\section{DISCUSSION}

We used acoustic telemetry to assess entrainment vulnerability of adult bull trout and burbot in a hydropower reservoir. One major challenge in this study was the low and temporally variable detection efficiency of the VR2Ws deployed in the forebay, which was possibly caused by noise emanating from the turbines. Indeed, detection efficiency of acoustic receivers is known to be reduced by and vary with environmental noise (Gjelland \& Hedger 2013), leading to erroneous interpretations of animal behaviour and habitat use if left unaccounted for (Payne et al. 2010). In our case, failure to account for the seasonally varying detection efficiency would have resulted in the conclusion that forebay use by adult bull trout and burbot was as high as, or higher, in the spring compared with the fall and winter-a finding that would be inconsistent with the observed seasonal pattern of entrainment (i.e. higher in the fall and winter). Our approach to account for detection efficiency was to compute the ratio between the number of detections of a tagged fish relative to the number of detections that would be expected from a hypothetical fish residing exclusively in the forebay (i.e. represented by $\mathrm{pDF}$ or $\% \mathrm{DF})$. The expected number of detections was simulated assuming that fish show no preference for specific locations in the forebay (see the Supplement), being thus likely to visit the vicinity of each VR2W equally. However, if in reality, fish preferentially used areas of the forebay where less efficient VR2Ws were located (i.e. those located near the powerhouse), then our approach might have led to underestimates of \%DF. Conversely, \%DF might have been overestimated if fish preferentially used areas away from the powerhouse, where VR2Ws tended to be more efficient. However, we cannot assess the extent to which \%DF was affected by the 
spatial distribution of fish in the forebay and the values presented here should be seen as a relative measure of forebay use. Given the limitations imposed by low and variable detection efficiency in assessing forebay use by fish in this research, we suggest that future studies on entrainment vulnerability consider using acoustic telemetry based on code division multiple access $\left(\mathrm{CDMA}_{i}\right.$ Niezgoda et al. 2002) or other coding schemes and frequencies that may be less affected by noise than the acoustic telemetry equipment used in this study.

Forebay use by adult bull trout was typically very low (median \% DF $<1$ ), with only 4 out of 97 individuals having $\% \mathrm{DF}>50$. Although generally low, forebay use was markedly seasonal, being highest in the fall and winter. The seasonal pattern of forebay use by bull trout is consistent with their migratory movements related to spawning and post-spawning (Dunham et al. 2008). In both fluvial (i.e. river residents) and adfluvial (i.e. lake or reservoir residents) bull trout, a fraction of the population migrates towards tributaries in late spring and summer, spawn in the late summer and early fall, and return to the mainstem of rivers or lakes/reservoirs by mid fall to overwinter (e.g. Fraley \& Shepard 1989, Swanberg 1997). As bull trout return to overwinter in the deep pools of Kinbasket Reservoir, they are likely to search for habitats with increased availability of prey to replenish their energy reserves spent during migration and spawning. The forebay of Kinbasket Reservoir is possibly an area of increased prey availability during fall and winter, as the flows generated by the maximization of turbine operations in these seasons could, by advection or attraction, congregate invertebrates and fish prey near the dam (e.g. Maiolie \& Elam 1996, Hiebert et al. 2003). Indeed, the density of age 0-1 (8 to $18 \mathrm{~cm}$ ) kokanee Oncorhynchus nerka, one of the main prey for adult bull trout, increases along the dam face of Revelstoke Reservoir (150 km downstream of Kinbasket Reservoir) with increasing operational discharge (Dawson \& Parkinson 2013). However, in the absence of fall and winter data for kokanee abundance and distribution in Kinbasket Reservoir, it is not possible to conclusively identify prey resource use as the mechanism responsible for the seasonally dependent variations in forebay use and, hence, entrainment vulnerability.

Consistent with the increased use of the forebay in the fall and winter, 7 out of 8 entrained tagged bull trout were first detected on the tailrace VR2Ws in those seasons. Although data from this study point to low annual entrainment rates (about $3.4 \%$ ), entrainment rates are highly site specific (Coutant \& Whit- ney 2000), varying with reservoir type, dam structure and operation. Thus, direct comparisons of the estimated entrainment rates at the Mica Dam with entrainment rates observed in other systems are not straightforward. Nonetheless, telemetry studies conducted at Arrowrock Dam (Idaho, USA), which forms a reservoir used primarily for recreation, irrigation and flood control, have found annual entrainment rates of adult bull trout ranging from 4.0 to $11.3 \%$ (Flatter 1998, Salow \& Hostettler 2004). Salow \& Hostettler (2004) reported that 7 out of 8 entrainment events occurred between the fall and winter, when operational discharge at the dam was higher than average and the intakes were only at $<10 \mathrm{~m}$ of depth. Several other entrainment studies have used various trapping techniques to capture fish at the tailrace of dams and reported an absence or low proportion of trout in the catch (James 2002, Hiebert et al. 2003, Spinelli 2010, see also review in CH2M HILL 2007). In many cases, the trout species caught were small $(<300 \mathrm{~mm})$ and the investigators could not determine if they were entrained fish or residents of the rivers/lakes downstream of the dams.

The population-level consequences of bull trout entrainment have been investigated in the Rimrock Reservoir (Tieton Dam, Washington, USA) by Underwood \& Cramer (2007). The authors developed a deterministic life cycle model to simulate the population-level consequence of entrainment of subdaults (1.4\% annual entrainment rate) and adults $(0.5 \%)$ in the presence of harvesting ( $4 \%$ annual harvest rate). Simulation results showed that the population was resilient to these levels of entrainment and harvest due to the high fecundity of bull trout, which allowed the simulated population to quickly rebound from the losses. However, the annual rate of adult entrainment assumed in that study was nearly 7 times lower than that observed in our study $(3.4 \%)$. Future studies should investigate the sensitivity of simulations of population abundance to higher and varying levels of adult entrainment rates, as well as to variation in life history and harvest rate parameters, and incorporate the effects of environmental and demographic stochasticity (Lande et al. 2003).

Burbot used the forebay even less than bull trout. Although median \%DF was similar between the 2 species, the maximum \%DF observed for burbot was about $2 \%$, whereas \%DF values between 10 and $55 \%$ were observed for bull trout. Although the forebay detection data for burbot were too sparse to enable us to formally evaluate seasonal patterns in $\% \mathrm{DF}$, it is noteworthy that burbot detections in the forebay during the second monitoring year occurred 
only in the fall - the period when we observed the lowest levels of detection efficiency of the forebay VR2Ws over the $2 \mathrm{yr}$ of study (Fig. S4, Table S1 in the Supplement). Furthermore, the only entrainment event recorded for a tagged burbot occurred in the fall of the first monitoring year. These limited but important findings suggest that burbot are more likely to encounter and use the forebay in the fall. The increased entrainment vulnerability at this time of the year might be associated with the general observation that burbot movement is greater during the fall, presumably due to increases in feeding activity before spawning (Carl 1995, Paragamian \& Wakkinen 2008). Few studies have investigated entrainment of burbot at other dams (e.g. Libby Dam and Hauser Dam, Montana), but what has been done indicates increased entrainment in the summer and fall, though entrained fish were mostly juveniles (Skaar et al. 1996, Spinelli 2010).

\section{SUMMARY AND CONCLUSIONS}

Collectively, our findings revealed that (1) adult bull trout and burbot made little use of the forebay; (2) bull trout used the forebay more and had higher rates of entrainment than burbot; and (3) both forebay use and entrainment varied among seasons, particularly so for bull trout. Bull trout seem to be at higher risk of entrainment during the fall and winter, whereas limited evidence indicates that burbot would be at higher risk of entrainment during the fall. These findings should be applicable for adult bull trout and burbot in other hydropower reservoirs, particularly if water diversion is maximized in the fall and winter, when bull trout are overwintering in the lake and burbot seem more active due to increases in pre-spawning feeding. Given that bull trout are listed as threatened in the United States (USFWS 1999) and considered of special concern or threatened in 3 of 5 biogeographic populations in Canada (COSEWIC 2012), the impacts of additional mortality due to entrainment of adults on the long-term viability of reservoir populations warrant further investigation, which will enable both managers and industry to make informed decisions on how to mitigate and compensate for entrainment.

Acknowledgements. We thank J. Tippe, J. Molina, J. Hills, T. Nettles, G. Crossin, J. Nitychoruk, J. Thiem and S. Landsman for helping in the field. R. Brown and 2 anonymous reviewers provided helpful comments to improve this manuscript. This research was funded by the Natural Sciences and Engineering Research Council of Canada (via NSERC HydroNet and a Collaborative Research and Development Grant and a discovery grant to M.P. and S.J.C.), BC Hydro and the Center for Expertise on Hydropower Impacts of Fish and Fish Habitat of Fisheries and Oceans Canada. S.J.C. is supported by the Canada Research Chairs Program. Some of the telemetry infrastructure was provided by the Canada Foundation for Innovation and the Ontario Ministry of Research and Innovation. We also thank P. Higgins, K. Smokorowski, D. Boisclair and S. O'Connor for supporting the project.

\section{LITERATURE CITED}

Beeman JW, Perry RW (2012) Bias from false-positive detections and strategies for their removal in studies using telemetry. In: Adams NS, Beeman JW, Eiler JH (eds) Telemetry techniques: a user guide for fisheries research. American Fisheries Society, Bethesda, MD, p 505-518

BC Hydro (2006) Mica Dam entrainment risk screening. BC Hydro, Burnaby, BC

BC Hydro (2009) Mica-Revelstoke fish entrainment strategy action plan. MCA-REV Fish Entrainment Strategy Technical Committee, BC Hydro, Burnaby, BC

Bray K (2012) Kinbasket and Revelstoke reservoirs ecological productivity monitoring. Progress report year 3 (2010) CLBMON-3. BC Hydro, Burnaby, BC. Available at www. bchydro.com/content/dam/hydro/medialib/internet/ documents/planning_regulatory/wup/southern_interior/ 2012q1/clbmon-3_yr3_2012-01-01.pdf

CH2M HILL (2007) Potential for resident trout entrainment in Spada Lake, Washington. Report prepared for Public Utility District No. 1 of Snohomish County and City of Everett, Everett, WA. Available at www.snopud.com/ Site/Content/Documents/relicensing/Study\%20Reports/ Jackson2157_SP4_Final_Technical_Report_Dec2007.pdf

Carl LM (1995) Sonic tracking of burbot in Lake Opeongo, Ontario. Trans Am Fish Soc 124:77-83

Cooke SJ, Hinch SG, Lucas MC, Lutcavage M (2013) Biotelemetry and biologging. In: Zale, AV, Parrish DL, Sutton TM (eds) Fisheries techniques, 3rd edn. American Fisheries Society, Bethesda, MD

COSEWIC (Committee on the Status of Endangered Wildlife in Canada) (2012) Canadian wildlife species at risk. Available at www.cosewic.gc.ca/eng/sct2/index_e.cfm (accession date 21 February 2013)

$>$ Coutant CC, Whitney RR (2000) Fish behavior in relation to passage through hydropower turbines: a review. Trans Am Fish Soc 129:351-380

Dawson J, Parkinson E (2013) Revelstoke Reservoir kokanee behavior and entrainment rate assessment. Report prepared for BC Hydro, Burnaby, BC

Dunham J, Baxter C, Fausch K, Fredenberg W and others (2008) Evolution, ecology, and conservation of dolly varden, white-spotted char, and bull trout. Fisheries (Bethesda, MD) 33:537-550

Flatter B (1998) Life history and population status of migratory bull trout (Salvelinus confluentus) in Arrowrock Reservoir, Idaho. Report prepared for US Dept of the Interior, Bureau of Reclamation, Pacific Northwest Region, Boise, ID. Available at https://collaboration.idfg.idaho. gov/FisheriesTechnicalReports/Res98-07Flatter1998\% 20Life $\% 20$ History $\% 20$ and $\% 20$ Population $\% 20$ Status $\% 20$ of $\% 20$ Migratory $\% 20$ Bull $\% 20$ Trout $\% 20$ Salvelinus $\% 20$ 
confluentus \%20in\%20Arrowrock\%20Reservoir.pdf

Fraley JJ, Shepard BB (1989) Life history, ecology and population status of migratory bull trout (Salvelinus confluentus) in the Flathead Lake and River system, Montana. Northwest Sci 63:133-143

Gjelland KØ, Hedger RD (2013) Environmental influence on transmitter detection probability in biotelemetry: developing a general model of acoustic transmission. Method Ecol Evol 4:665-674

$>$ Grimaldo LF, Sommer T, Van Ark N, Jones G and others (2009) Factors affecting fish entrainment into massive water diversions in a tidal freshwater estuary: Can fish losses be managed? N Am J Fish Manage 29:1253-1270

Gutowsky LFG, Harrison PM, Landsman SJ, Power M, Cooke SJ (2011) Injury and immediate mortality associated with recreational troll capture of bull trout (Salvelinus confluentus) in a reservoir in the Kootenay-Rocky Mountain region of British Columbia. Fish Res 109: 379-383

> Hanson KC, Gravel MA, Graham A, Shoji A, Cooke SJ (2008) Sexual variation in fisheries research and management: When does sex matter? Rev Fish Sci 16:421-436

Harrell FE (2001) Regression modelling strategies: with applications to linear models, logistic regression and survival analysis. Springer-Verlag, New York, NY

Harrison PM, Gutwosky LFG, Martins EG, Patterson DA, Power M, Cooke SJ (2013) Spatial behaviour of bull trout and burbot in Kinbasket Reservoir. Report prepared for BC Hydro, Burnaby, BC

Helfman GS (1993) Fish behaviour by day, night and twilight. In: Pitcher TJ (ed) Behavior of teleost fishes, 2nd edn. Chapman \& Hall, London, p 479-512

Hiebert S, Best E, Sechrist J, Swartz R, Moore D, Wilson J, Kennedy S (2003) Fish entrainment from Rimrock Reservoir Tieton River, Washington 2002. US Dept of the Interior, Bureau of Reclamation, Denver, CO. Available at www.ybfwrb.org/Assets/Documents/References/Hiebert _et_al_2002.pdf

Hothorn T, Bretz F, Westfall P (2008) Simultaneous inference in general parametric models. Biom J 50:346-363

James PW (2002) Rimrock Lake fish entrainment study 2001: final report. Report prepared for US Dept of the Interior, US Bureau of Reclamation, Yakima, WA. Available at www.ybfwrb.org/Assets/Documents/References/James_ 2002b.pdf

> Johnson GE, Hedgepeth JB, Skalski JR, Giorgi AE (2004) A Markov chain analysis of fish movements to determine entrainment zones. Fish Res 69:349-358

Kareiva PM, Shigesada N (1983) Analyzing insect movement as a correlated random walk. Oecologia 56:234-238

Lande R, Enger S, Sæther BE (2003) Stochastic population dynamics in ecology and conservation. Oxford University Press, Oxford

Maiolie M, Elam S (1996) Kokanee entrainment losses at Dworshak Reservoir: Dworshak Dam impacts assessment and fisheries investigation project, 1996 Annual Report, Project No. 198709900. Report prepared for Bonneville Power Administration, Portland, OR. Available at https://pisces.bpa.gov/release/documents/ documentviewer.aspx?doc $=35167-10$

> Mathur D, Heisey PG, Skalski JR, Kenney DR (2000) Salmonid smolt survival relative to turbine efficiency and entrainment depth in hydroelectric power generation. J Am Water Resour Assoc 36:737-747

- Neufeld MD, Spence CR (2004) Evaluation of a simple de- compression procedure to reduce decompression trauma in trap caught burbot. Trans Am Fish Soc 133:1260-1263

Niezgoda G, Benfield M, Sisak M, Anson P (2002) Tracking acoustic transmitters by code division multiple access (CDMA)-based telemetry. Hydrobiologia 483:275-286

Paragamian VL, Wakkinen VD (2008) Seasonal movement of burbot in relation to temperature and discharge in the Kootenai River, Idaho, USA and British Columbia. In: Paragamian VL, Bennett DH (eds) Burbot: ecology, management and culture. American Fisheries Society, Bethesda, MA, p 55-77

Payne NL, Gillanders BM, Webber DM, Semmens JM (2010) Interpreting diel activity patterns from acoustic telemetry: the need for controls. Mar Ecol Prog Ser 419:295-301

Pinheiro JC, Bates DM (2000) Mixed-effects models in S and S-Plus. Springer-Verlag, New York, NY

Pinheiro J, Bates D, DebRoy S, Sarkar D, R Development Core Team (2012) nlme: linear and nonlinear mixed effects models. R package version 3.1-104. Available at http://cran.r-project.org/web/packages/nlme/index.html

Quinn GP, Keough MJ (2002) Experimental design and data analysis for biologists. Cambridge University Press, Cambridge

R Development Core Team (2012) R: a language and environment for statistical computing. $\mathrm{R}$ Foundation for Statistical Computing, Vienna. www.r-project.org

> Ross ST (1986) Resource partitioning in fish assemblages: a review of field studies. Copeia 1986:352-388

Salow T, Hostettler L (2004) Movement and mortality patterns of adult adfluvial bull trout (Salvelinus confluentus) in the Boise River basin Idaho. Report prepared for Arrowrock Dam Valve Replacement Project and US Dept of the Interior, Bureau of Reclamation, Boise, ID. Available at www.usbr.gov/pn/snakeriver/esa/bulltrout/reports/ 2004-Arrowrockvalveradiotelemetry.pdf

Schilt CR (2007) Developing fish passage and protection at hydropower dams. Appl Anim Behav Sci 104:295-325

Scott WB, Crossman EJ (1998) Freshwater fishes of Canada. Galt House Publications, Oakville, ON

Scruton D, McKinley R, Kouwen N, Eddy W, Booth R (2002) Use of telemetry and hydraulic modeling to evaluate and improve fish guidance efficiency at a louver and bypass system for downstream-migrating Atlantic salmon (Salmo salar) smolts and kelts. Hydrobiologia 483:83-94

> Scruton DA, Pennell CJ, Bourgeois CE, Goosney RF and others (2008) Hydroelectricity and fish: a synopsis of comprehensive studies of upstream and downstream passage of anadromous wild Atlantic salmon, Salmo salar, on the Exploits River, Canada. Hydrobiologia 609:225-239

Sebastian D, Scholten G, Addison D, Labelle M, Green D (1995) Results of the 1991-1993 hydroacoustic surveys at Mica and Revelstoke Reservoirs. Stock Management Unit Report No. 1. Province of British Columbia, Ministry of Environment, Lands and Parks, Victoria, BC

Skaar D, DeShazer J, Garrow L, Ostrowski T, Thomburg B (1996) Quantification of Libby Reservoir levels needed to maintain or enhance reservoir fisheries: investigations of fish entrainment through Libby Dam, 1990-1994. Report prepared for US Department of Energy and Bonneville Power Administration Environment, Fish and Wildlife, Portland, OR. Available at http.//docs.streamnetlibrary. org/BPA_Fish_and_Wildlife/12660-6.pdf

Spinelli JP (2010) Spatial and temporal entrainment of fish from Hauser Reservoir, Montana. MSc thesis, Montana State University, Bozeman, MT. Available at http:// 
scholarworks.montana.edu/xmlui/handle/1/2332 (accessed 21 August 2012)

Swanberg TR (1997) Movements of and habitat use by fluvial bull trout in the Blackfoot River, Montana. Trans Am Fish Soc 126:735-746

Therneau $\mathrm{T}$ (2012) A package for survival analysis in S. $\mathrm{R}$ package version 2.36-14. Available at http://cran.rproject.org/web/packages/survival/index.html (accessed 15 July 2012)

Thorne RE, Johnson GE (1993) A review of hydroacoustic studies for estimation of salmonid downriver migration past hydroelectric facilities on the Columbia and Snake Rivers in the 1980s. Rev Fish Sci 1:27-56

Underwood K, Cramer SP (2007) Simulation of human effects on bull trout population dynamics in Rimrock Reservoir, Washington. Am Fish Soc Symp 53:191-207

Editorial responsibility: L. Asbjørn Vøllestad, Oslo, Norway
USFWS (United States Fish and Wildlife Service) (1999) Endangered and threatened wildlife and plants: determination of threatened status for bull trout in the coterminous United States. Final Rule. 50 CFR Part 17. Fed Regist 64:58910-58933

Wagner GF, Cooke SJ, Brown RS, Deters KA (2011) Surgical implantation techniques for electronic tags in fish. Rev Fish Biol Fish 21:71-81

Warton DI, Hui FKC (2011) The arcsine is asinine: the analysis of proportions in ecology. Ecology 92:3-10

Zuur AF, Ieno EN, Walker NJ, Saveliev AA, Smith GM (2009) Mixed effects models and extensions in ecology with R. Springer, New York, NY

Zuur AF, Ieno EN, Elphick CS (2010) A protocol for data exploration to avoid common statistical problems. Method Ecol Evol 1:3-14

Submitted: May 31, 2013; Accepted: August 21, 2013

Proofs received from author(s): October 22, 2013 